\title{
A EXPRESSÃO DOS FENÔMENOS ÉTICOS EM WITTGENSTEIN
}

\author{
Lucas Jairo Cervantes Bispo ${ }^{1}$; Wagner Teles de Oliveira ${ }^{2}$; \\ 1. Bolsista PROBIC/UEFS, Graduando em Filosofia, Universidade Estadual de Feira de Santana, e-mail: \\ ljcbispo@outlook.com \\ 2. Orientador, Departamento de Ciências Humanas e Filosofia, Universidade Estadual de Feira de Santana, e-mail: \\ woteles@gmail.com
}

PALAVRAS-CHAVE: Wittgenstein; fenômenos éticos; limites do sentido.

\section{INTRODUÇÃO}

Ludwig Wittgenstein, no Tractatus Logico-Philosophicus, através de uma crítica da proposição, traça os limites do pensamento. De acordo com a perspectiva do Tractauts, esses limites só poderiam ser traçados no âmbito da linguagem, de tal modo que tudo o que venha a ultrapassá-lo seria um contrassenso. A partir da estrutura da linguagem, então, infere-se a estrutura do mundo, comprendendo a linguagem proposicional como uma imagem de um estado de coisas possível ao qual ela deve identificar-se, o que quer dizer haver uma relação de isomorfia entre as partes mínimas da proposição e as partes mínimas do fato do qual ela é uma imagem. Por ser figuração de um fato do mundo, a proposição é, a fim de representá-lo, marcada pela contingência, preservando a possibilidade de ser verdadeira ou falsa. A partir da redução do dizível à forma de enunciados declarativos, Wittgenstein encerra no domínio do que não se deixa dizer todas aquelas condições lógicas que possibilitam a elaboração do discurso significativo. Por visar ao absoluto, a ética não poderia ganhar corpo na forma de um discurso significativo na medida em que tudo o que se deixa dizer, porque contingente, deve poder ser negado. Todavia, apesar da indizibilidade da Ética e de não haver fatos Éticos no mundo, já que tudo o que pode ser dito pertence ao campo do significativo e remonta a fatos mundanos, não só Wittgenstein atribui relevância à Ética, como assume haver fenômenos éticos, isto é, ações que se pretendem éticos. Não fica claro, então, qual seria o estatuto desses fenômenos, justificando-se assim a interrogação pelo estatuto de tais fenômenos e também sobre a possibilidade da Ética ganhar expressão numa modalidade de linguagem que não fosse ela mesma proposicional. Nessa medida, dado a redução, feita pelo Tractatus da linguagem a modalidade de enunciados declarativos, convém perguntar também se o Tractatus não deixaria margem à existência de outras formas de expressão em que os fenômenos éticos tivessem lugar.

\section{MATERIAL E MÉTODOS OU METODOLOGIA (ou equivalente)}

O método consistiu na leitura e escrita de textos segundo técnicas de exegese e de escrita que caracterizam a atuação profissional na área. Assim, a execução das atividades concernidas pelo plano de trabalho privilegiou o cotejo das fontes primárias da pesquisa, sem se furtar à apreciação de fontes secundárias. Nesse sentido, houve a etapa de leituras e fichamentos, depois de escrita e apresentação no Grupo de Estudo e Pesquisa para apreciação dos resultados parciais da pesquisa por meio do debate das questões que ela envolve.

\section{RESULTADOS E/OU DISCUSSÃO (ou Análise e discussão dos resultados)}

Wittgenstein, no prefácio do Tractatus Logico-Philosophicus, revela ser sua pretensão traçar um limite para a expressão dos pensamentos, o qual, segundo ele, só poderia ser traçado no âmbito da linguagem. Assim, tudo que viesse a ultrapassar esse limite seria um contra-senso. Não se trata, portanto, como ele próprio fará questão de ressalvar, de traçar um limite para o pensar, pois se fosse assim, a tarefa de demarcação 
implicaria inevitavelmente traçar os dois lados do limite, ou seja, implicaria pensar o que não pode ser pensado de acordo com a própria demarcação.

Nessa mesma direção, o cerne do Tractatus consistiria na doutrina do dizer e do mostrar, o que o insere na tradição crítica, pois envolve fundamentalmente a demarcação entre o que pode ser dito e o que pode apenas ser mostrado. O espírito que move essa demarcação do campo do sentido é tramado em relação com a análise do pensamento por meio de sua manifestação sensível, que é a proposição, afinal de contas, também tal análise só pode ser feita no âmbito da linguagem, e não do próprio pensamento.

Para Wittgenstein, tudo que pode ser dito deixa-se expressar na forma de proposições com sentido, de modo que os enunciados que não satisfazem as condições lógicas destas ocupam o lugar do indizível, como é o caso das proposições da Ética. A proposição é assim compreendida como uma figuração de um estado de coisas ao qual ela deve identificar-se ponto a ponto, configurando uma relação de isomorfia entre as partes mínimas da proposição e as partes mínimas do fato do qual ela pretende ser a representação. Por isso mesmo, por ser figuração de um fato do mundo, a proposição só pode mesmo, a fim de lograr o propósito de representá-lo, ser essencialmente marcada pela contingência, o que quer dizer que ela deve preservar a possibilidade de ser verdadeira ou falsa. Por visar ao absoluto, a Ética não poderia ganhar corpo na forma de um discurso proposicional com essas condições, na medida em que tudo que se deixa dizer, porque contingente, deve poder também ser negado.

No entanto, Wittgenstein não deixará de notar que a Ética é relevante, o que faz sua demarcação criar uma cisão entre o absoluto e o relativo, fazendo também ver como os domínios do significativo e do relevante não coincidem. E é exatamente por essa razão que aquelas questões mais importariam a vida, desse ponto vista, seriam sequer tocadas caso todos os problemas científicos tivessem sido resolvidos. Afinal, a ciência, toda ela, estaria circunscrita no domínio do que pode ser dito.

Não haver coincidência entre o significativo e o relevante articula, na verdade, a concepção pictórica da proposição que caracteriza o Tractatus e, por conseguinte, mobiliza todo o projeto de demarcação do campo do significativo do qual ele pretende ser a realização. Com a distinção entre o significativo e o relevante, desse modo, o Tractatus parece reduzir a linguagem ao âmbito do significativo. A Ética, enquanto pertencente ao domínio do que é relevante, escaparia, por essa perspectiva, do domínio do significativo, não se deixando, portanto captar pela linguagem proposicional.

\section{CONSIDERAÇÕES FINAIS (ou Conclusão)}

Ao compreendermos a Conferência Sobre Ética como uma extensão do Tractatus Logico-Philosophicus, essa se revela um texto que reforça, esclarece e desenvolve as noções mais fundamentais deste outro quanto à delimitação do que pode ou não ser expresso com sentido pela linguagem, acerca do que seria a ética e quais expressões tem caráter ético ou não. Ética que, por sua vez, tanto no Tractatus LogicoPhilosophicus como na Conferencia Sobre Ética, está fora do âmbito do dizível, dado que não satifaz as condições já expostas para que pudesse ser dita com sentido.

A partir das considerações anteriores, podemos entender a Ética como indizível. Isso pressupõe e implica que não existem fatos éticos, pois se existissem poderiam ser representados proposicionalmente e a Ética seria dizível. Assim, se não há fatos Éticos, 
as expressões que se pretendem éticas não podem ser objetivas e passíveis do atributo de verdade ou falsidade, no primeiro caso no sentido de "objetivo" como "uma coisa ou a um ser que tem existência ontológica real, ou seja, existe fora da mente" (HEGENBERG, 2010) e no segundo no sentido de verdade ou falsidade como correspondência ou não entre representação proposicional e a existência do fato representado. Em acréscimo, a partir da Conferência Sobre Ética, sabemos que não há fatos éticos exteriores, como também os estados mentais enquanto fatos descritíveis não possuem sentido ético, implicando numa inexistência de objetividade interior.

Entretanto, apesar dessa resposta negativa quanto ao estatuto dos fenômenos éticos poder ser inferida da nossa investigação, não há uma resposta positiva, por exemplo afirmando que esses fenômenos seriam subjetivos, no Tractatus ou na Conferência. O que pode ser sustentado, do ponto de vista de Wittgenstein nessas obras, é apenas que a Ética se mostra.

O conceito de "mostrar", num primeiro sentido, em Wittgenstein, tem a ver com aquilo que os sinais não expressam, mas que aparece em seu emprego. Ou seja, o uso do signo revela coisas indizíveis pelo próprio signo. E como todo uso é uma ação, ações mostram. Haveria, portanto, algo fora do mundo como totalidade dos fatos e da linguagem como totalidade das proposições verdadeiras e falsas: aquilo que não pode ser dito, pois não ocorre no mundo, não é um fato.

De acordo com Hans-Johann Glock (1998), inicialmente, aquilo que não pode ser dito mas somente mostrado seriam as propriedades lógicas da linguagem, todavia a distinção entre dizer e mostrar cria uma extensão para, ao meu ver, um segundo sentido e que se refere à esfera do místico, contrastando as proposições empíricas da ciência não somente com a lógica e a metafísica, mas com a esfera do valor, ou seja, a ética, a estética e a religião.

Ocorre que se por um lado quanto essas propriedades lógicas da linguagem apareceriam na utilização da própria linguagem, ainda que não possam elas mesmas serem representadas linguisticamente, ainda segundo Hans-Johann Glock a Ética só se mostraria através das ações, não havendo qualquer signo que pudesse mostrar o valor Ético.

Assim, parece correto concluir, como implicação, que respostas as questões Éticas não podem ser pensadas, não podendo ganhar expressão na linguagem. Que não podemos fazer ciência e nem há verdade ou falsidade quanto a Ética, e que não é possível distinguirmos diferentes ações éticas do ponto de vista da justiça, dado ser a própria justiça uma questão ética fora do campo do sentido. 


\section{REFERÊNCIAS}

DALL'AGNOL, Darlei. Ética e Linguagem: uma introdução ao Tractatus de Wittgenstein. São Leopoldo. Editora Unisinos, 2005. P. 2013-224.

DARWALL, Stephen; GIBBARD, Allan; RAILTON, Peter. Metaética: algumas tendências. Organização de Darlei Dall'Agnol; tradução de Janine Sattler. Florianópolis: Editora UFSC, 2013, 317 páginas. 1998.

GLOCK, Hans-Johann. Dicionário Wittgenstein. Rio de Janeiro: Jorge Zahar,

HALLER, Rudolf. A Ética no Pensamento de Wittgenstein. Trad. Peter Naumann. Revisão Técnica de Noberto Abreu e Silva Neto. Revista Estudos Avançados 11 (5), 1991.

HEGENBERG, L. Filosofia Moral: Metaética. Vol. 2. Rio: E-papers, 2010. MORENO, Arley R. Wittgenstein: os labirintos da linguagem: ensaio introdutório. São Paulo: Moderna, 2000.

PINTO, Paulo Roberto Margutti. Iniciação ao silêncio: uma análise do Tractatus de Wittgenstein. São Paulo: edições Loyola (coleção Filosofia), 1998.

SANTOS, Luiz Henrique Lopes dos. "A Essência da Proposição e a Essência do Mundo”. In: Tractatus Logico-Philosophicus, Edusp, São Paulo, 2008.

WITTGENSTEIN, Ludwig. Tractatus Logico-Philosophicus. 3.ed.2.reimp. São Paulo: EDUSP, 2010.

WITTGENSTEIN, Ludwig. "Conferência sobre Ética”. In: DALL'AGNOL, Darlei. Ética e Linguagem: uma introdução ao Tractatus de Wittgenstein. São Leopoldo. Editora Unisinos, 2005. P. 2013-224. 